\title{
Exploring the tutor-student interaction in a blended university course
}

\author{
Tatiana Krasnova ${ }^{\text {a }}$, Anna Popova \\ National Research Tomsk Polytechnic University, Institute of Cybernetics, 634050 Lenin Avenue 30, Russia
}

\begin{abstract}
A meaningful tutor-student interaction requires a new insight into pedagogical principles and proper implementation of modern teaching strategies. This paper aims to contribute to the understanding of online tutoring in blended learning settings and the impact of the tutor-student interaction on the learning process. The article reports on the results of the study on students' evaluation of the tutor's role and the tutor-student interaction in a blended university course. The findings show that professional tutoring and the effective tutor-student interaction help students to improve their learning efficacy and to have a greater personal responsibility for their outcomes.
\end{abstract}

\section{Introduction}

Due to advances in information and communication technologies, education has experienced the greatest revolution. E-learning has appeared to be at the core of this revolution offering a variety of useful tools for educators and aiming to solve old problems of traditional education. E-learning has transformed the student's role from being passive to becoming an active agent in the learning process, which is now turned into a lifelong experience. But the introduction of e-learning in isolation from traditional instruction gave a feeling of disillusionment as the first results were not satisfying and promising. Inefficiency of e-learning could be caused by a lot of different factors: technological, methodological, organizational and didactic ones. But the most significant factor that hindered the learning process was lack of a teacher-student interaction. The impact of such interaction can be seen in a blended learning model, where e-learning is combined with traditional face-to-face instruction. Key tools of human communication (body language, eye contact, etc.) are present in traditional face-to-face settings but, what is more, teachers continue to provide individual emotional and encouraging support by creating the "situation of presence" in the e-learning mode.

The teacher in the online environment obtains a special mission of the tutor who guides the students and supports the learning process. Thus, the teacher takes a role of a facilitator and a mentor, while students are still responsible for their outcomes. Tutors in blended learning cease to be the source of information for students; they help to understand the essence of the learning process and the mechanisms of acquiring

\footnotetext{
a Corresponding author: krasnova@tpu.ru
}

knowledge, as a result, students are capable of performing more advanced tasks.

Many studies show strong correlation between online tutoring and increased student efficiency. Duggleby believes that by providing a proper climate online, tutors make learners take the responsibility for their learning and complete the course successfully [1]. According to Hughes good learner support can target 'at-risk' learners and improve retention [2]. MacDonald emphasizes the central role of the tutor in a blended strategy. He believes that in addition to formal contacts, tutors have contacts on the informal level and view them as a valued opportunity to keep up with individual student progress [3].

The tutor teaches and guides students as they move through a huge amount of information, helps to analyze and synthesize the course material, organizes collaboration and interaction of the participants of the learning process. Bender in her book characterizes such tutor's style as being supportive and encouraging, giving ample feedback, being a good role model, being appropriately informal, and eliciting discussion [4]. King and Schank think that social rather than technical factors often determine the success or failure of an online course $[5,6]$. The tutor should contribute time and efforts for creating a friendly interactive learning environment.

Achieving a meaningful tutor-student interaction requires proper implementation of modern teaching strategies where the goals of learning, the type of skills and abilities to be developed and the desired level of cognition should be taken into consideration [7]. 


\section{Online tutoring in blended learning environment}

There exists a common opinion that blended learning frees tutors from a great amount of work because of automated assessment in the online course. But reality is far from this belief; on the contrary, the tutors invest even more time in creating viable online activities and in their own professional development, in order to adapt their teaching to accommodate the new technologies, and in tutoring itself [8]. A blended learning approach is energy-intensive for tutors who have to acquire both pedagogical and technological skills. They find themselves under an increasing pressure when their "virtual' activity is not clearly seen but demands a lot of effort and time. Indeed, teaching workload increases, professional requirements rise and management control functions become more complicated. Using a blended learning method induces tutors to constantly increase professional expertise, master computer skills, create new online courses, and contribute much time to lesson preparation.

Specific policies concerning blended learning appear in many Russian academic institutions in order to meet modern educational challenges. National Research Tomsk Polytechnic University (TPU) has a clear concept of quality blended learning investing not only in technology but in teachers' development and methodology. Without this trio of elements, the tool itself is pointless, which is the worst possible outcome in training terms [7].

TPU administration is trying to equip the academic staff with essential knowledge and skills to operate effectively in emerging e-learning environments. Moodle was chosen to maintain blended learning in TPU. In the course placed on Moodle platform students spend some time independently assimilating learning materials, taking quizzes, fulfilling different assignments and interacting with other students [9]. However, placing different online activities, simulations, games, discussions in some Learning Management System (LMS) does not guarantee meaningful interaction in the online course. Without new insight into pedagogical principles, it is impossible to create an interactive collaborative environment.

But how to achieve this much-talked-about interaction? The first step is to understand the changed role of tutors shifted from a knowledge transmitter to a facilitator. They should guide students rather than manage and control them. Tutors should understand when students need their support and when students want to enjoy the process of self-discovery [10].

Complex monitoring and analysis of students' performance online is the essential part of the tutorstudent interaction. Teachers' awareness of what and how learners are doing is important to assess learner progress [11]. Certain analytic tools of the Moodle platform give a possibility to keep track of the progress made by students. Most often they extract information from users' generated logs. An excellent graphical interface of these tools give a complete overview of students' steps making them easy to analyse. Userfriendly plugins provide tutors with progress reports including grades, submissions, feedback, attendance, etc.

One of such prevalent Moodle applications for tutors is Dashboard presented as a block that captures and visualizes course performance in an aggregated form (a linear and tabular table, a tree view, different types of graphs, timelines, etc.). Many new learning analytic tools appear nowadays (Intelliboard, Smartklass ${ }^{\mathrm{TM}}$, Configurable Reports, GISMO, etc.); they facilitate analysis of the students' interaction and empower tutors to manage their learning trajectories. Tutors can identify lagging behind students and help them immediately by giving extra support and eliminating knowledge gaps. Students for whom the content is not challenging enough can also be easily tracked and provided with more advanced activities.

This instant analysis allows taking into account individual characteristics of students, thus creating optimal conditions for realization of their individual potential. Moodle assignments can be adjusted to individual talents and abilities of students, such as proficiency, memory capabilities, and skills. These activities help weak students to get engaged in a collaborative work and impose high requirements to the strong ones. Such close tutor-student collaboration increases the level of activity of each student and contributes to their efficiency.

Thus, real time analytic tools help tutors to take immediate actions and contact the students in order to improve the outcomes. The same analytic tools can be used by students to learn about their performance, compare it with the group and understand where they need to enhance their learning process.

One more way to help students to manage the course activities is to adjust a time management plugin called Progress Bar. The research carried out by Aycock, Garnham, \& Kaleta showed that students' psychological maturity and time management skills can also be a problem even more significant than any technology difficulties [12]. Progress Bar displays students' progress in an interactive way. It provides a colour coded display of the required actions with the expected date. Students control their own performance and track whether they completed the tests and assignments on time or not. Using different analytic tools which complement each other by adding new functionalities can help to reach their full potential and contribute to adjusting learning strategies and the overall tutor-student interaction.

The blended course is very flexible; its distinctive feature is the efficiency of information accordance. It takes months or even years to renew a textbook that is the main source of information in traditional learning, while the tutor can change or add new material every day to keep it up-to-date. For instance, it is very encouraging to generate discussions on current issues using forums. This surely motivates the students by showing them the relevance of what they are studying and how it applies to the 'outside world' [13]. Thus the course can be easily tailored to the needs of the students. All these changes can be made in accordance with students' requests when they discuss different alternatives with the tutor. 
Moodle asynchronous forums are known as the greatest collaborative tool where it is possible to create threads of discussions. In asynchronous discussion environment students communicate, cooperate and share knowledge. There are different ways of implementing discussion forums in the online course. They can be used for social interaction only, for discussion of assignments or other tasks, for collaboration when preparing an individual project, or as a central part of the teaching strategy [14].

Tutors analyse participation in forums and assess the contribution of each student. They also can take a leading role in discussion and moderate it. But the degree to which the tutors should be involved in discussions is still under consideration. Some researchers believe that too active intervention in discussions could reduce the student-student interaction.

Another element of the tutor-student interaction is a feedback which can be motivational (when the tutor influences student's behaviour by encouraging) and developmental (when the tutor facilitates the learning process).

Motivational feedback in the form of constant encouragement is very important for an online course, it is vital that students' efforts are monitored and estimated. Online communication is different from faceto-face interaction in that it does not employ any paralinguistic features, such as gestures and facial expressions to praise students. Thus, it is essential to give individual feedback and complement individual and group achievements in order to motivate and encourage students to further challenges.

Most practitioners who have experience of teaching using the blended learning method admit that timely feedback to students is one of the main factors that makes the course successful. It is essential for a teacher to be involved into the interaction with students, troubleshooting and a problem solving process. The researchers think that the importance of creating a sense of presence in online teaching and learning environments cannot be overestimated [15]. This is quite a hard job for a tutor as this sense of presence should be intentionally created, which means being with online learners throughout their learning experience. By giving feedback the students become involved into the design process, shape the online environment and can greatly affect the future of the course.

Developmental feedback can become a key to students' satisfaction with the learning process. This type of feedback can give students clear information on whether they are attaining the previewed goals or not, as well as identification of the mistakes they are making and what they are lacking [16]. Espasa investigated feedback given by tutors after assignments of the course and elaborated four semantic dimensions of feedback:

- identification and correction of errors;

- correct response;

- improving the task;

- in-depth information [17].

The effect of developmental feedback should not be underestimated, as it notifies students about their problems and directs them to further understanding of the course content.

\section{Research methods}

The traditional TPU foreign languages teaching model incorporates 128 hours of face-to-face practical sessions and 88 hours of online training in Moodle during the semester.

In order to understand how the students see the tutorstudent interaction in online courses, a survey was conducted. By the end of the survey period, data had been collected from 48 individuals, 42 of whom were male and 6 female. The course chosen for study was called "Business English Blended Course" intended for second-year students studying at the Institute of Cybernetics at TPU. This was a course of English as a foreign language at the intermediate and upperintermediate undergraduate level; it ran from September to June and equated to $68 \%$ of one year's full time study. The online part of the course strongly correlated with the face-to-face sessions and was intended to reinforce them. The course was created and coordinated by one tutor who had broad experience in creating learning content and online tuition. The online course contained quizzes with instant feedback, written assignments with delayed feedback and assessment, workshops with peer assessment, collaborative wikis, discussion forums and HotPots activities. Online course participation was quite intensive, on average there were 562 logs per student during the semester. Each activity was equipped with feedback and comment tools, moreover Moodle provided the message service by means of which tutors and students could contact each other and communicate. The tutor always answered within less than 12 hours. The communication flow was very rich and contributed a lot to the establishing of interactive collaborative environment.

At the end of the course, the participants answered an evaluation questionnaire. The questionnaire contained 6 questions trying to evaluate the tutor-student interaction and tutor performance in the online course.

\section{Results and analysis}

Students' responses informed that they mostly prefer moderate supervision from course tutors $(89,6 \%)$, some students wanted self-directed learning with minimum tutor assistance $(8,3 \%)$ and one student wished guided online learning with maximum tutor support $(2,1 \%)$. According to their answers, we see that students want to take the initiative for their learning and to be more independent. Thus tutors should provide a climate where students can take responsibility for their learning, where they can develop the knowledge, confidence and skills required to become more independent learners.

All the interviewees indicated that they used some analytic tools to monitor their performance. Progress Bar was called the most informative and useful tool. One respondent alluded that this plugin helped combat his procrastination habit. By adjusting this tool, the tutor 
made students proceed systematically in the learning process.

The participants, on the whole, demonstrated technical adaptability and preferred to solve technical problems on their own as they were students of Computer Science department. But still they indicated that the tutor-student interaction regarding technical issues was of great importance. The Moodle interface was easy to use and most of the respondents $(95,8 \%)$ reported that they did not have any difficulties exploiting the course and did not need any additional help from tutors in understanding the instructions for the activities.

Receiving feedback from a tutor was highly appreciated by students. According to students' opinions, immediate feedback was important only in quizzes when the students wanted to see and analyze their mistakes. But simple identification of mistakes did not fully satisfy the students, they needed tutor's comments in the test, links to corresponding rules and other information about how to improve the completed task. The majority of those who responded to this item felt that in the feedback after tests and assignments tutors should contribute detailed information to help students look deeper into the content.

As for assignment evaluation and other types of tutor's feedback, delayed support was quite a normal option. But delayed individual feedback focusing on particular students' problems was not usually expected; students wanted just grading and error correction. They considered constructive and prompt feedback to be more important than criticism and praise. Only 10, 4\% percent of respondents reported that motivational feedback after assignments was of great value for them.

Some participants expressed the belief that feedback can be excessive and may influence negatively the learning process. In this case, the tutor risks losing the facilitator role and obtaining the role of an information provider, thus returning to a teacher-centered approach. But nobody reported about the excessive feedback in the completed course, the respondents called all tutor's interventions necessary.

When the participants were asked about tutor's participation in discussions, nearly half of students (45, $8 \%$ ) believed that tutors should take part in online discussions to encourage students and engage in the dialogue with each other by thought provoking questions. They should boost in sharing ideas, opinions and information from authentic sources. But the other greater part of students $(54,2 \%)$ did not want active interference of the tutor in their communication. They agreed only on minimum participation of the tutors who could just give a positive feedback, a compliment or make them feel that their contribution was valuable, but they were against of their directing the thread of the discussion.

The findings highlight the necessity of the tutorstudent interaction in online courses in order to create safe and comfortable learning environment. The learning process should be focused on the student who is supported in his or her study. Professional tutor support should favor the development of responsible attitude to study, motivation and time management.

\section{Conclusion}

New tendencies in the higher education system lead to reconsidering a teacher's role and position; they assume special features in the conditions of blended learning. Blended learning demands transformation of a traditional teacher into a tutor, who becomes more a coordinator or mentor but not a direct source of knowledge and information. The tutor of the blended course stimulates student's ability to self-knowledge and self-perfection.

The nature of online tutoring is very diverse, but the most crucial aspect is to scaffold students by creating a comfortable environment. The emphasis should be placed on the tutor-student interaction in order to create a context of collaborative and active learning. The online course benefits from flexible design, as tutors can adapt course content to meet individual students' needs. Tutor's feedback should become a fundamental part of the online course as it helps to produce better results in future and has a great motivational stimulus.

\section{References}

1. Duggleby, J. How to be an online tutor. Gower Publishing, Ltd., (2000).

2. Hughes, G. Using blended learning to increase learner support and improve retention. Teaching in Higher Education, 12 (3), 349-363. (2007).

3. MacDonald, J. Blended learning and online tutoring: Planning learner support and activity design. Gower Publishing, Ltd., (2008).

4. Bender, T. Discussion-based online teaching to enhance student learning. Sterling, Virginia: Stylus Publishing, (2003).

5. King, F. B. A virtual student. Not an ordinary Joe. Internet and Higher Education, 5, 157-166. (2002).

6. Schank, R. Educational technology: The promise and the myth. World Bank, Human Development Network, Education Group, Washington, DC Processed, (2001).

7. García-Peñalvo, F. J. ed. Advances in E-Learning: Experiences and Methodologies: Experiences and Methodologies. IGI Global, (2008).

8. Donnelly, R., ed. Applied e-learning and e-teaching in higher education. IGI Global, (2009).

9. Krasnova, T., Vanushin, I. Blended Learning Perception among Undergraduate Engineering Students. International Journal of Emerging Technologies in Learning (iJET), 11 (1), 54-56 (2016).

10. Throne, K. Blended Learning: How to Integrate Online \& Traditional Learning. London: Kogan Page Limited, (2003).

11. Papamitsiou, Z., \& Economides, A. Temporal learning analytics visualizations for increasing awareness during assessment. RUSC. Universities and Knowledge Society Journal, 12 (3), 129-147 (2015).

12. Aycock, A., Garnham, C., \& Kaleta, R. Lessons learned from the hybrid course project. Teaching with Technology Today, 8(6), 1-6. (2002). 
13. Nehme, M. E-learning and students' motivation. Legal Educ. Rev. 20 (2010).

14. Mazzolini, M., \& Maddison, S. Sage, guide or ghost? The effect of instructor intervention on student participation in online discussion forums. Computers \& Education, 40(3), 237-253, (2003).

15. Lehman, R. M., \& Conceição, S. C. Creating a sense of presence in online teaching: How to" be there" for distance learners (Vol. 18). John Wiley \& Sons, (2010).

16. Martínez-Argüelles, M., Plana, D., Hintzmann, C., Batalla-Busquets, J., \& Badia, M. Usefulness of feedback in e-learning from the students' perspective. Intangible Capital, 11(4), 627-645, (2015).

17. Espasa, A. Temporal and assessment dimension: characterization of feedback after assignments. eLearn Center Research Paper Series, 1, 17-29, (2010). 